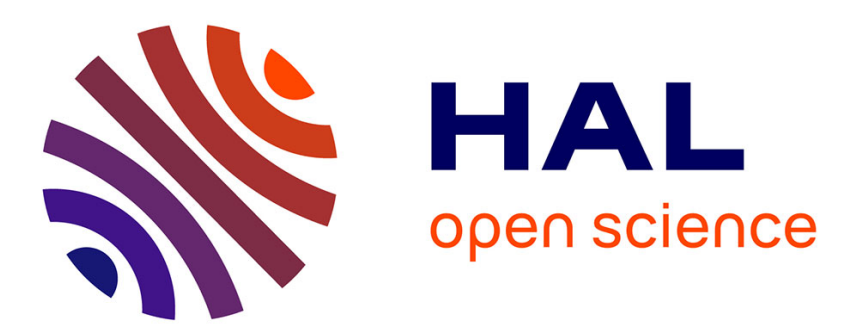

\title{
Effects of black carbon content, particle size, and mixing on light absorption by aerosols from biomass burning in Brazil
}

J. Vanderlei Martins, Paulo Artaxo, Catherine Liousse, Jeffrey Reid, Peter Hobbs, Yoram Kaufman

\section{To cite this version:}

J. Vanderlei Martins, Paulo Artaxo, Catherine Liousse, Jeffrey Reid, Peter Hobbs, et al.. Effects of black carbon content, particle size, and mixing on light absorption by aerosols from biomass burning in Brazil. Journal of Geophysical Research: Atmospheres, 1998, 103 (D24), pp.32041-32050. 10.1029/98JD02593 . hal-03119661

\section{HAL Id: hal-03119661 \\ https://hal.science/hal-03119661}

Submitted on 25 Jan 2021

HAL is a multi-disciplinary open access archive for the deposit and dissemination of scientific research documents, whether they are published or not. The documents may come from teaching and research institutions in France or abroad, or from public or private research centers.
L'archive ouverte pluridisciplinaire HAL, est destinée au dépôt et à la diffusion de documents scientifiques de niveau recherche, publiés ou non, émanant des établissements d'enseignement et de recherche français ou étrangers, des laboratoires publics ou privés. 


\title{
Effects of black carbon content, particle size, and mixing on light absorption by aerosols from biomass burning in Brazil
}

\author{
J. Vanderlei Martins, ${ }^{1,2,3}$ Paulo Artaxo, ${ }^{1}$ Catherine Liousse, ${ }^{4}$ Jeffrey S. Reid, ${ }^{2}$ \\ Peter V. Hobbs, ${ }^{2}$ and Yoram J. Kaufman ${ }^{3}$
}

\begin{abstract}
Black carbon mass absorption efficiencies of smoke particles were measured for various types of biomass fires during the Smoke, Clouds, and Radiation-Brazil (SCAR-B) experiment using thermal evolution measurements for black carbon and optical absorption methods. The obtained results range between 5.2 and $19.3 \mathrm{~m}^{2} \mathrm{~g}^{-1}$ with an average value of $12.1 \pm 4.0 \mathrm{~m}^{2} \mathrm{~g}^{-1}$. Particle size distributions and optical properties were also measured to provide a full set of physical parameters for modeling calculations. Mie theory was used to model the optical properties of the particles assuming both internal and external mixtures coupling the modeling calculations with the experimental results obtained during the campaign. For internal mixing, a particle model with a layered structure consisting of an absorbing black carbon core, surrounded by a nonabsorbing shell, was assumed. Also, for internal mixing, a discrete dipole approximation code was used to simulate packed soot clusters commonly found in electron microscopy photographs of filters collected during the experiment. The modeled results for layered spheres and packed clusters explain black carbon mass absorption coefficients up to values of about $25 \mathrm{~m}^{2} \mathrm{~g}^{-1}$, but measurements show even higher values which were correlated with the chemical composition and characteristics of the structure of the particles. Unrealistic high values of black carbon absorption efficiencies were linked to high concentrations of $\mathrm{K}$, which influence the volatilization of black carbon $(\mathrm{BC})$ at lower temperatures than usual, possibly causing artifacts in the determination of $\mathrm{BC}$ by thermal technique. The modeling results are compared with nephelometer and light absorption measurements.
\end{abstract}

\section{Introduction}

Light absorption by aerosol particles has a heating effect in the atmosphere, which contrasts with the cooling effect by nonabsorptive particles. The balance between the cooling and the heating effects depends on the absorption and scattering properties of the particles. Smoke particles produced by biomass burning have a significant fraction of light-absorbing material composed by black carbon particles. Black carbon is the only important absorber to be taken into account in radiative transfer calculations of smoke aerosols. The same amount of $\mathrm{BC}$ for different types of mixing may result in fairly different absorption properties. The efficiency with which a certain amount of $\mathrm{BC}$ will absorb light is expressed by a $\mathrm{BC}$ mass absorption efficiency $\left(\alpha a_{\mathrm{BC}}\right)$. This coefficient relates the amount of $\mathrm{BC}$ in the particle with the light absorption cross section and depends on the size of particles and on the type of mixing between $\mathrm{BC}$ and nonabsorbing components (such as organic matter and sulfates). In external mixtures consisting of individual pure $\mathrm{BC}$ particles in parallel with nonabsorbing particles, the $\mathrm{BC}$ mass absorption efficiency is, in general, about

\footnotetext{
'Instıtuto de Física, Universidade de São Paulo, Sāo Paulo, Brazil. ${ }^{2}$ Department of Atmospheric Sciences, University of Washington, Seattle.

${ }^{3}$ NASA Goddard Space Flight Center, Greenbelt, Maryland.

${ }^{4}$ Centre de Farbles Radıoactivites, CNRS-CEA, Gif sur Yvette, France.

Copyright 1998 by the American Geophysical Union.

Paper number 98JD02593.

0148-0227/98/98JD-02593\$09.00
}

the same as for pure BC particles. However, for smoke aerosol, it is likely that $\mathrm{BC}$ particles that form at relatively high temperatures will be coated by a nonabsorbing shell (to form an internal mixture). The external shell is likely formed by gasto-particle conversion and condensation of volatile compounds. Thus a reasonable model for biomass burning particles is a layered sphere, with a highly absorbing BC core surrounded by a nonabsorbing shell.

Ackerman and Toon [1981] explored the optical properties of internal and external mixtures using the layered-sphere model and volume-homogeneous mixtures, where the absorbing material is homogeneously mixed with nonabsorbing compounds. Another type of internal mixture commonly found in smoke aerosols are long-chain aggregates of $\mathrm{BC}$ particles formed at high temperatures close to the fire. These chain aggregates can also be coated with nonabsorbıng materials to form an internally mixed heterogeneous structure. After aging and interactions with water vapor and clouds, these opened clusters usually collapse to form closely packed spherical-like structures [Hallet et al., 1989]. These packed structures are likely to be externally coated and also have nonabsorbing material in its internal structure. Figure 1 shows examples of some possible internal and external mixtures of $\mathrm{BC}$ particles and nonabsorbing materials in smoke from biomass fires.

In the present study, we use Mie theory to estimate the mass absorption efficiency of BC particles internally and externally mixed with nonabsorbing materials. Calculations for particles with a layered structure were performed using a Mie code developed by Ackerman and Toon [1981], as further developed and made available by $\mathrm{W}$. Wiscombe. Closely packed BC clus- 


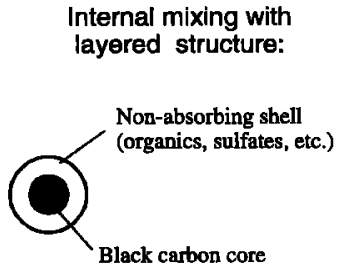

External mixing:
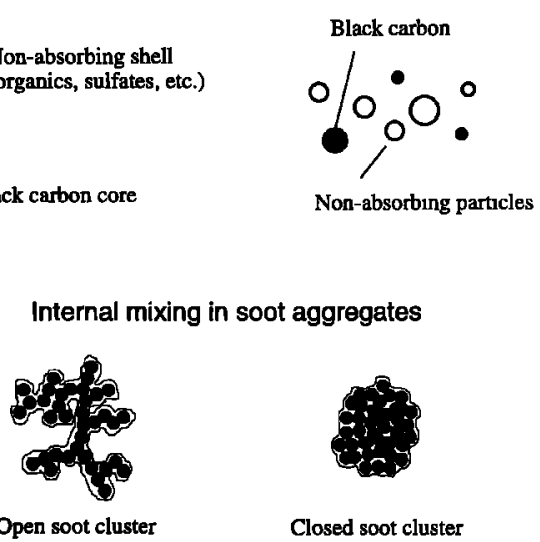

Figure 1. Examples of some possible mixtures between black carbon (BC) and nonabsorbing materials in smoke particles.

ters were simulated by a three-dimensional mathematical structure with thousands of dipoles, the optical properties of which were calculated using the discrete dipole approximation [Draine and Flatau, 1994; Purcell and Pennypacker, 1973]. Dipole calculations were performed using the code DDSCAT, made available by B. Draine and P. Flatau. Results from closed clusters are compared with those from the layered-sphere model and with the Maxwell-Garnett average field theory for homogeneous internally mixed materials [Bohren and Huffman, 1983]. The modeling results are compared with measurements of BC mass absorption efficiency obtained during the SCAR-B field project in Brazil.

\section{Theoretical Modeling}

The mass absorption efficiency of an aerosol particle $(\alpha a)$ is defined as the absorption coefficient of the particles $\left(\mathrm{m}^{-1}\right)$ divided by the particle mass concentration $\left(\mathrm{g} \mathrm{m}^{-3}\right)$. Similarly, the $\mathrm{BC}$ mass absorption efficiency $\left(\alpha a_{\mathrm{BC}}\right)$ is defined as the absorption coefficient of the particles $\left(\mathrm{m}^{-1}\right)$ divided by the mass concentration of black carbon $\left(\mathrm{g} \mathrm{m}^{-3}\right)$ in the aerosol. The BC mass absorption efficiency indicates how efficiently a cer-

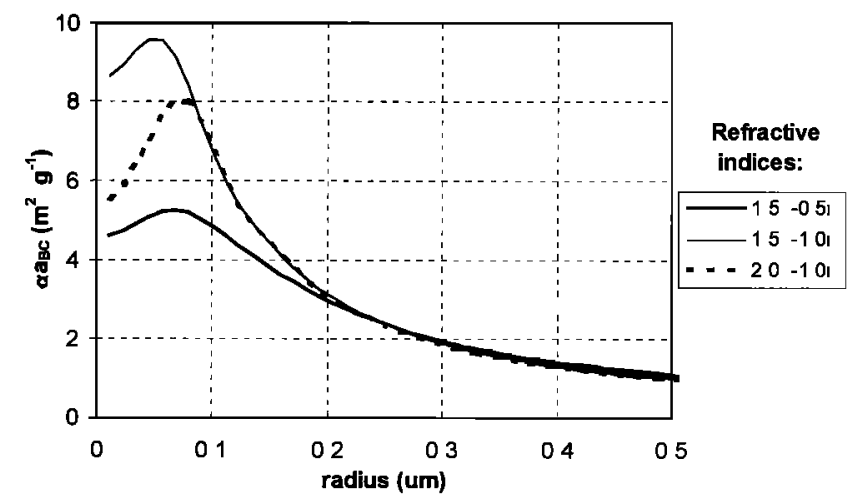

Figure 2. Calculated values of black carbon mass absorption efficiency $\left(\alpha a_{\mathrm{BC}}\right)$ for pure $\mathrm{BC}$ spherical particles (density $1.85 \mathrm{~g} \mathrm{~cm}^{-3}$ ) at a wavelength of $0.55 \mu \mathrm{m}$. Three complex refractive indices $(n)$, spanning values commonly found in the literature, were used in these calculations $(n=1.5-0.5 l, n=$ $1.5-1.0 i$, and $n=2.0-1.0 i$ ). tain amount of $\mathrm{BC}$ absorbs light for different types of particle mixing and sizes. Figure 2 shows Mie calculations of the $\mathrm{BC}$ mass absorption efficiency for pure BC spheres (at $\lambda=0.55$ $\mu \mathrm{m})$ as a function of the particle radius. The $\mathrm{BC}$ mass absorption efficiency for pure BC particles $\left(\rho=1.85 \mathrm{~g} \mathrm{~cm}^{-3}\right)$ remains below $10 \mathrm{~m}^{2} \mathrm{~g}^{-1}$, regardless of particle size and for three values of the complex refractive index covering the range commonly found in the literature [Horvath, 1993a]. Calculations of the BC mass absorption efficiencies over a realistic accumulation mode biomass burning particle size distribution [e.g., Reid et al., this issue (b)] produces values much lower than $10 \mathrm{~m}^{2} \mathrm{~g}^{-1}$. Internally mixed particles composed of an absorbing core surrounded by a nonabsorbing shell have, in general, a greater BC mass absorption efficiency than pure BC particles. This is because the nonabsorbing shell increases the total cross-sectional area of the particle and focuses light toward the absorbing core, causing the same amount of $\mathrm{BC}$ in the mixed structure to absorb more than pure $\mathrm{BC}$ particles.

Figure 3 shows calculated $\mathrm{BC}$ mass absorption efficiency for particles with a $\mathrm{BC}$ core surrounded by a nonabsorbing shell. Along the text, shell radius is defined as equal to the particle radius. It can be seen that for particles with a layered structure the value of $\alpha a_{\mathrm{BC}}$ depends on the fraction of $\mathrm{BC}$ in each particle and on the size of the particles, but it can be much larger than that for pure BC particles. For the studied parameters, the larger the particle radius the larger the effect of the nonabsorbing coating in $\alpha a_{\mathrm{BC}}$, up to a maximum $\alpha a_{\mathrm{BC}}$ value for a particle radius of about $0.25 \mu \mathrm{m}$. For a $\mathrm{BC}$ fraction of $0.5 \%$, and monodispersed particles with an external radius of $0.25 \mu \mathrm{m}, \alpha a_{\mathrm{BC}}$ can reach values as high as $30 \mathrm{~m}^{2} \mathrm{~g}^{-1}$. The different behavior as a function of the shell radius can be explained by the relative size of the $\mathrm{BC}$ core, which is determined by the fraction BC/TPM (black carbon divided by total particle mass), the external particle radius, and the density of each component. The shell radius is also important in determining the value of the mass absorption coefficient. For a particle radius about $0.05 \mu \mathrm{m}$, the $\mathrm{BC}$ mass absorption effi-

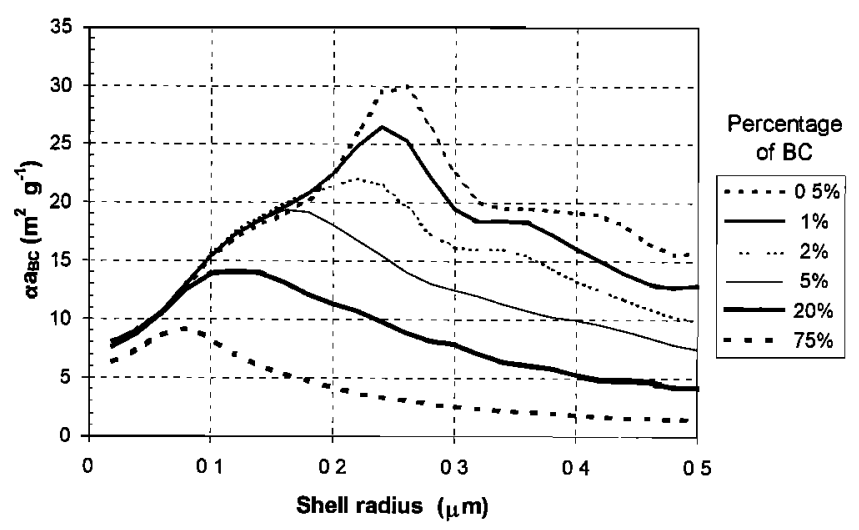

Figure 3. Calculated values of black carbon mass absorption efficiency $\left(\alpha a_{\mathrm{BC}}\right)$ at $\lambda=0.55 \mu \mathrm{m}$ for an internal mixture of BC and nonabsorbing material in a layered structure. The particle structure consists of an absorbing $\mathrm{BC}$ core with a surrounding nonabsorbing shell. The refractive index of the $\mathrm{BC}$ was assumed to be $2.0-1.0 i$, the density $1.85 \mathrm{~g} \mathrm{~cm}^{-3}$; for the nonabsorbing shell, the refractive index was assumed to be 1.5$10^{-6} i$ and the density $1.5 \mathrm{~g} \mathrm{~cm}^{-3}$. The amount of $\mathrm{BC}$ and the radius of the shell determine the radius of the $\mathrm{BC}$ core. The radius of the shell is defined in this work as equal to the radius of the particle. 


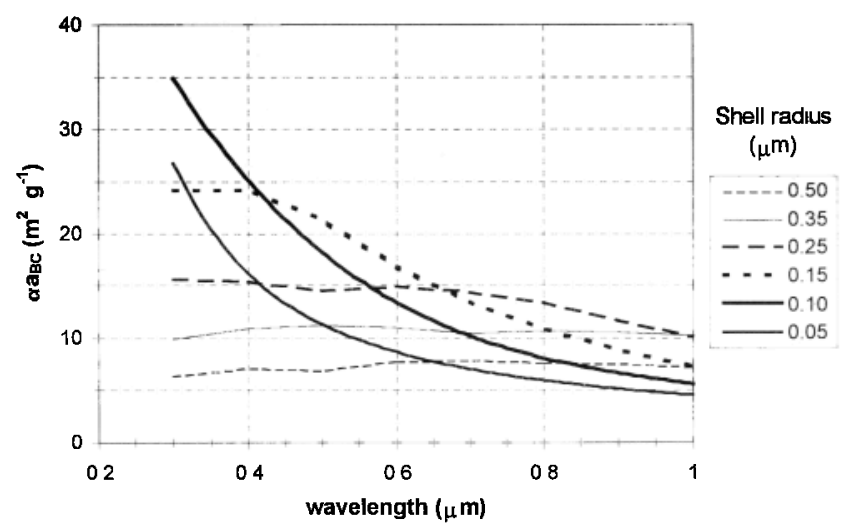

Figure 4. Calculated values of black carbon mass absorption efficiency $\left(\alpha a_{\mathrm{BC}}\right)$ as a function of the wavelength for several particle radii based on Mie calculations for the layered-sphere model. Particle structure is an absorbing BC core (5\% in mass) and a nonabsorbing external shell. Optical parameters are the same as for Figure 3.

ciency is around $10 \mathrm{~m}^{2} \mathrm{~g}^{-1}$ and is almost independent of the ratio BC/TPM. Several authors obtained values around $10 \mathrm{~m}^{2}$ $\mathrm{g}^{-1}$ for $\alpha a_{\mathrm{BC}}$ of aerosol particles [Clarke et al., 1987; Japar et al., 1986; Roessler and Faxvog, 1980]. The value of $\alpha a_{\mathrm{BC}}$ is also dependent on the real part of the refractive index of the nonabsorbing shell. For a range of real refractive indices around values reported in the literature for organic materials and sulfate, higher refractive indices will produce higher values of $\alpha a_{\mathrm{BC}}($ at $\lambda=0.55 \mu \mathrm{m}$ ).

Spectral measurements of light absorption associated with measurements of the particle size distributions can be useful in determining the type of mixing between $\mathrm{BC}$ and nonabsorbing particles. The wavelength dependence of the light absorption depends on the sizes of the absorbing particles. Figure 4 shows an example of the spectral dependence of the $\mathrm{BC}$ mass absorption efficiency for several particle sizes based on the layeredsphere model with an absorbing core and a nonabsorbing shell with $5 \% \mathrm{BC}$ in mass. The results show that smaller particles ( 0.05 to $0.15 \mu \mathrm{m}$ ) have stronger wavelength dependence for light absorption than larger particles. This suggests that spectral measurements of light absorption by aerosol particles can provide information on the type of mixing and on the size of the absorbers.

Other factors, such as the shape and structure of the particles, can affect the BC mass absorption efficiency. Black carbon is commonly found in large chain aggregates close to the fires. The optical properties of these fresh aggregates have been estimated to be equivalent to individual pure $\mathrm{BC}$ particles. These aggregates can also have a nonabsorbing external layer, and after interacting with water vapor and clouds, they can collapse to form more closely packed structures [Hallet et al., 1989]. Scanning electron microscopy (SEM) photographs show that in some cases, most of the particles in regional hazes in Brazil are composed of compact closed clusters, with the particle radius varying over the whole size distribution [Martins et al., this issue]. These closed structures have different optical properties from the initial fresh chain aggregates. Depending on size ranges and structures, the $\mathrm{BC}$ mass absorption efficiency for these packed clusters with a nonabsorbing layer will be larger than those of pure BC particles.

Figure 5a shows a transmission electron microscope (TEM) photograph of a smoke particle composed of a closed cluster aggregate and, apparently, a coating of lower density material. Figure $5 b$ illustrates the mathematical model we used to calculate the optical properties of such closed clusters using the discrete dipole approximation code (DDSCAT). Each dot in Figure 5 b represents a single dipole, with different symbols for

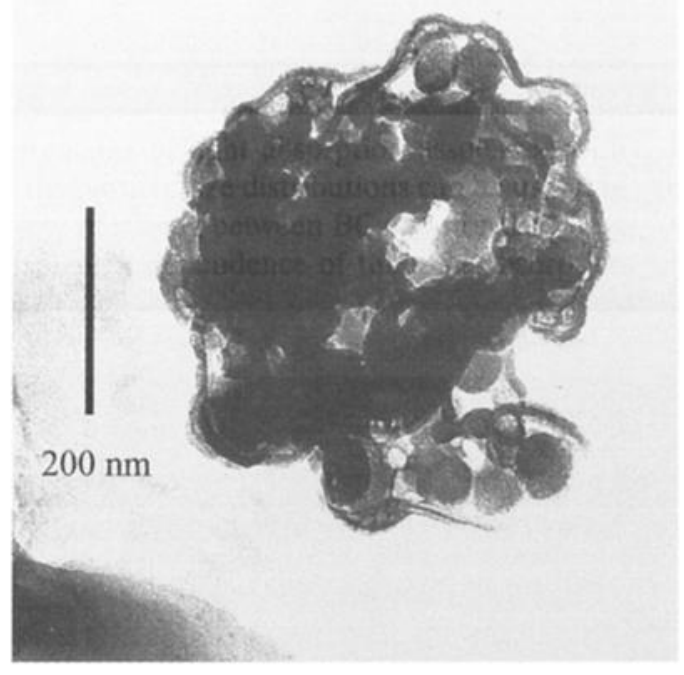

(a)

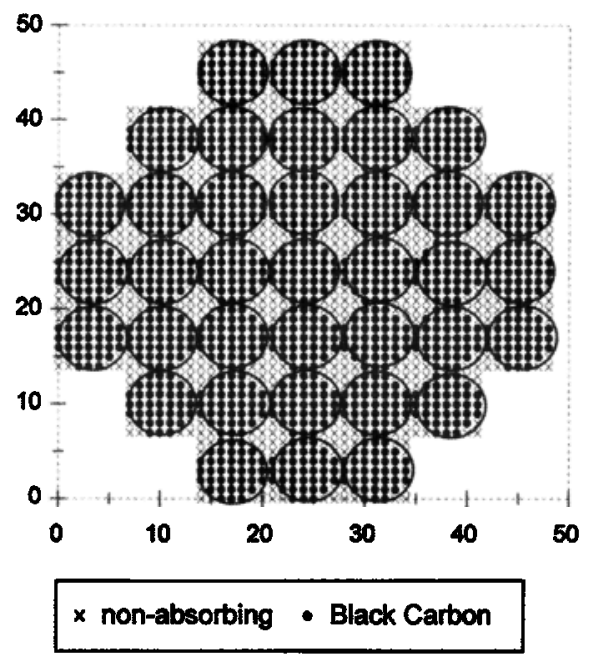

(b)

Figure 5. (a) Transmission electron microscopy photograph of a closely packed BC cluster from biomass burning. The structure shows evidences of a particle coating with a different material from that of the isolated spheres. Photograph courtesy of F. Echalar, Institute of Physics, University of Sāo Paulo. (b) Threedimensional mathematical structure used for simulating internal mixtures of a closely packed cluster using the discrete dipole approximation. Each dot in the figure represents a single dipole; the large circles composed of many dots correspond to single $\mathrm{BC}$ particles. 
$\mathrm{BC}$ and nonabsorbing materials. The black dots represent dipoles with the dielectric properties of $\mathrm{BC}$, the $\mathrm{x}$ symbols are dipoles with dielectric properties of nonabsorbing materials. A complex refractive index of 2.0-1.0 $i$ was assumed for BC and $1.5-1.0 \times 10^{-6} i$ for nonabsorbing particles, with densities of 1.85 and $1.5 \mathrm{~g} \mathrm{~cm}^{-3}$, respectively. The modeled structure is three dimensional with $\mathrm{BC}$ particles in touch with each other and all the free spaces filled with nonabsorbing material. This mixture results in a volume ratio $\left(V_{\mathrm{BC}} / V_{\text {tot }}\right)$ of 0.52 , which means that $\mathrm{BC}$ corresponds to $64 \%$ of the particle mass. It is important to recall that even if the bulk BC/TPM fraction in aerosols are of the order of $5-15 \%$, isolated particles may have a higher $\mathrm{BC}$ fraction depending on the particular mixture for each case (e.g., Figure 5a: particle is likely composed predominantly by $\mathrm{BC}$ ). The $\mathrm{BC}$ mass absorption efficiency $\left(\alpha a_{\mathrm{BC}}\right)$ for this structure was calculated using the DDSCAT code.

Figure 6 compares results from the packed cluster structure with $\alpha a_{\mathrm{BC}}$ for pure $\mathrm{BC}$ particles and for the layered-sphere model. For all particle radius, $\alpha a_{\mathrm{BC}}$ for the closed cluster is larger than for pure $\mathrm{BC}$ particles, with a peak of $10 \mathrm{~m}^{2} \mathrm{~g}^{-1}$ at a particle radius about $0.1 \mu \mathrm{m}$ for the given $\mathrm{BC} / \mathrm{TPM}$ ratio. The closed cluster also showed $\alpha a_{\mathrm{BC}}$ values up to $35 \%$ higher than results for the layered sphere model for particle radius larger than $0.1 \mu \mathrm{m}$. Moreover, also in Figure 6 these results are compared with results from the Maxwell-Garnett mean field theory. In this theory, one determines average dielectric functions for the composed material, which are then used in a Mie code for estimating optical properties. The mixing rule used for this calculation considers a two component mixture with a nonabsorbing matrix containing spherical absorbing inclusions pondered by volume. The Maxwell-Garnet theory and the mixing rule used in this work is described in details by Bohren and Huffman [1983]. Despite problems in determining average effective refractive indices for mixed materials, we present an intercomparison of the DDSCAT results and the mean field theory as an example of a simple model for a complex structure. Good agreement was found between the DDSCAT results and the Maxwell-Garnet theory combined with Mie calculations in estimating $\alpha a_{\mathrm{BC}}$ over a large range of particle sizes. There was also good agreement for the particle mass scattering coefficient, although this does not assure that the mean field theory will reproduce all the optical properties of closed clusters at any wavelength, mixing ratio, or particle size. By analogy with the layered-sphere model, a smaller mixing ratio will provide a large $\alpha a_{\mathrm{BC}}$ value. Extrapolations using the mean field theory suggest that these packed clusters should not reach $\alpha a_{\mathrm{BC}}$ values larger than $20 \mathrm{~m}^{2} \mathrm{~g}^{-1}$ for realistic particle sizes and mixing ratios. Therefore the obtained results are in the same range as those obtained with the layered-sphere model.

\section{Measurements}

\subsection{Techniques}

Black carbon mass absorption efficiencies for aerosol particles were obtained for all samples collected simultaneously in Nuclepore and Quartz filters during the Smoke, Clouds, and Radiation-Brazil (SCAR-B) experiment. The determination of $\alpha a_{\mathrm{BC}}$ depends on measurements of the absorption coefficient and $\mathrm{BC}$ mass concentration. Measurements of light absorption by aerosols have been discussed by many authors [e.g., Honath, 1993a, b; Clarke, 1982a, b; Clarke et al., 1987, 1996; Campbell et al., 1995; Campbell and Cahill, 1996; Hanel et al.,

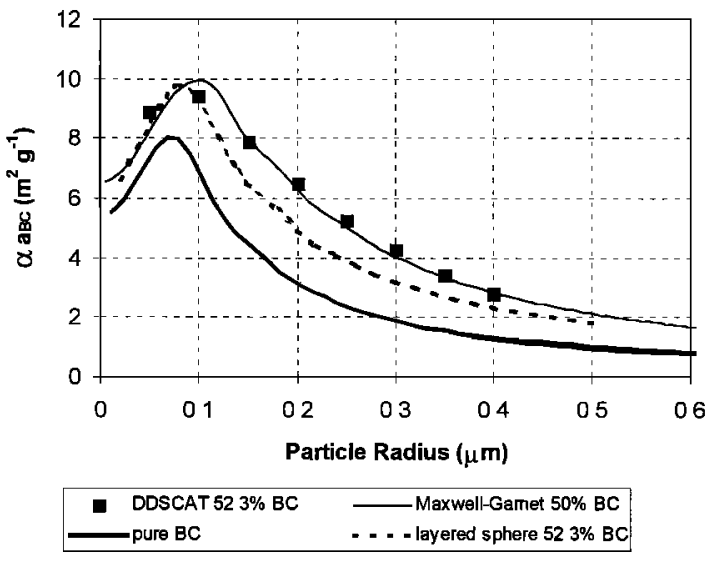

Figure 6. Calculated values of black carbon mass absorption efficiency for a BC cluster (at $\lambda=0.55 \mu \mathrm{m}$ ) with a nonabsorbing coating around individual particles versus the particle radius using the discrete dipole approximation (DDSCAT). Results from DDSSCAT are compared with pure BC particles (solid curve), layered-sphere model, and calculations using the Maxwell-Garnett theory considering a volume ratio of about 52 or $64 \%$ in mass.

1982; Delumyea et al., 1980]. Most of the methods applied on filters produce artifacts that depend on particle loading, type of filter, and type of particles but, on the other hand, have the advantage of concentrating the particles in a small volume for further analysis. The aethalometer technique combines automated optical attenuation measurements in filters with good tıme resolution depending on mass concentrations [Hansen et al., 1982; Ruoss et al., 1993]. Light absorption techniques require empirical calibrations and intercomparisons with different methods for quality assurance. During SCAR-B, light absorption was measured simultaneously by several techniques (optical extinction cell, integrating plate technique on Teflon filters, optical reflectance on Nuclepore filters, and absorption photometry or aethalometer technique) aboard the University of Washington (UW) C131-A aircraft; Reid et al. [this issue (a)] present an intercomparison of these techniques for the SCAR-B data set, considering a combination of the UW extinction cell plus a nephelometer as a reference methodology [Weiss and Hobbs, 1992]. Reid et al. [this issue (a)] concluded that for the various techniques used on the C-131A, optical reflectance (OR) provided the best correlation $(r=0.9)$ with light absorption measurements from the Weiss-Hobbs optical extinction cell (OEC) over several orders of magnitude. Reflectance techniques have been applied by other authors to obtain optical properties of aerosol particles [Lindberg and Laude, 1977; Patterson and Marshall, 1982]. Hanel [1988] discusses a photometric methodology for measuring light absorption by aerosol particles and concludes that its results are equivalent to a diffuse reflectance technique and to calorimetric measurements [Hanel and Hillenbrand, 1989].

Particulate carbon concentrations in the aerosol were determined by thermal analysis [Cachier et al., 1989] of quartz filters at the Centre de Faibles Radioactivites, CNRS-CEA, Gif sur Ivette, France. The exposed filters were subjected to $\mathrm{HCl}$ vapors for 24 hours in order to remove carbonates. The carbon remaining on the filters after this treatment is referred to as total atmospheric particulate carbon (TC). Both total and black carbon measurements were performed on filter aliquots 
by coulometric titration with a Stroblein Coulomat $\otimes^{8} 702 \mathrm{C}$. The black carbon fraction $\left(\mathrm{BC}_{\mathrm{Th}}\right)$ is analyzed after the thermal removal of the organic compounds at $340^{\circ} \mathrm{C}$ during $120 \mathrm{~min}$ under pure oxygen. $\mathrm{OC}$ is assumed to be the difference between TC and BC. It must be recalled, however, that the BC and OC separation is method dependent [Reid et al., this issue (a); Petzold and Niessner, 1995]. The published uncertainty in the $\mathrm{BC}$ content is of the order of $10 \%$ when $\mathrm{BC} / \mathrm{TC}$ ratio is in the $10-35 \%$ range, which corresponds to $70 \%$ of samples for the SCAR-B campaign. It must be noted that following Reid et al. [this issue (a)] and for the SCAR-B data set, BC concentrations could be increased by $25 \%$, due to thermal method sensitivity to catalytic reactions with $\mathrm{K}$ and $\mathrm{Na}$ [Novakov and Corrigan, 1995]. The Nuclepore, Quartz, and Teflon filters were collected in parallel in a grab-bag sampling system aboard the UW C131-A aircraft using the same inlet. Therefore because of sampling similarity with the quartz filters and good correlation with the OEC results $(r=0.9)$, absorption measurements from Nuclepore filters were considered in this work to calculate the absorption coefficients.

Several other aerosol properties were measured simultaneously, including particle size distributions, light scattering, and humidification factors [Hobbs, 1996; Reid et al., this issue (b); Reid and Hobbs, this issue]. Samples were collected in different conditions and environments, including smoke plumes, regional hazes, background air, and clouds. Nuclepore filters were also subjected to PIXE (proton-induced X-ray emission), SEM (scanning electron microscopy), and gravimetric analysis. The Teflon filters were analyzed gravimetrically and by ion chromatography. The elemental and ionic compositions provided information on the dependence of $\alpha a_{\mathrm{BC}}$ on the chemical composition of the particle, and the electron microscopy results provided information on the micromorphology and structure of the particles.

\subsection{Results}

Figure 7 shows a histogram of the measured BC mass absorption efficiencies for all the Nuclepore filters collected in parallel with quartz filters. The distribution of $\mathrm{BC}$ mass ab-

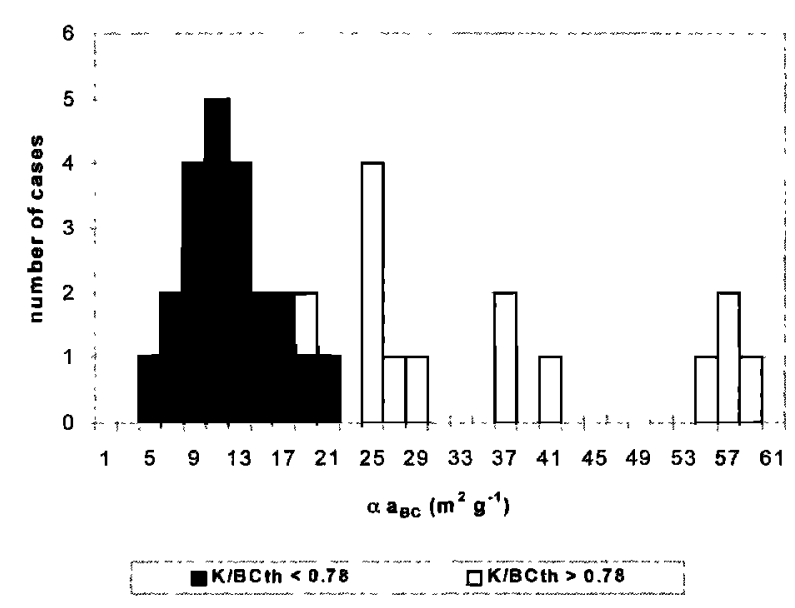

Figure 7. Histogram of measured BC mass absorption efficiencies obtained during SCAR-B. Results are separated in two groups with $\mathrm{K} / \mathrm{BC}_{\mathrm{Th}}<0.78$ and $\mathrm{K} / \mathrm{BC}_{\mathrm{Th}}>0.78$. As discussed in the text, estimates of $\alpha a_{\mathrm{BC}}$ were obtained based on the group with $\mathrm{K} / \mathrm{BC}_{\mathrm{Th}}<0.78$ producing an average $\alpha a_{\mathrm{BC}}=$ $12.1 \pm 4.0 \mathrm{~m}^{2} \mathrm{~g}^{-1}$ sorption efficiencies shows $\alpha a_{\mathbf{B C}}$ values between 5.2 and 58.2 $\mathrm{m}^{2} \mathrm{~g}^{-1}$ separated in two groups with distinct chemical signatures. The first group has a $\mathrm{K} / \mathrm{BC}_{\mathrm{Th}}$ ratio smaller than 0.78 and $\alpha a_{\mathrm{BC}}$ values between 5.2 and $19.3 \mathrm{~m}^{2} \mathrm{~g}^{-1}$, with an average value of $12.1 \pm 4.0 \mathrm{~m}^{2} \mathrm{~g}^{-1}$. The second group for $\mathrm{K} / \mathrm{BC}_{\mathrm{Th}}$ larger than 0.78 shows very scattered results for $\alpha a_{\mathrm{BC}}$ with values between 18.0 and $58.2 \mathrm{~m}^{2} \mathrm{~g}^{-1}$ and an average value of $37 \pm 14 \mathrm{~m}^{2} \mathrm{~g}^{-1}$. This separation is strongly observed in the relationship of $\alpha a_{\mathrm{BC}}$ and the concentrations of $\mathrm{K}, \mathrm{Ca}$, and $\mathrm{Mg}$ for each sample, as it can be seen in Figures $8 \mathrm{a}-8 \mathrm{c}$. High values of $\alpha a_{\mathrm{BC}}$ correlate well with high $\mathrm{K}, \mathrm{Ca}$, and $\mathrm{Mg}$ concentrations. According to Novakov and Corrigan [1995], K has a catalytic effect on $\mathrm{BC}$, lowering its volatilization temperature and causing artifacts on $\mathrm{BC}$ measurements obtained by thermal evolution techniques. This effect can explain the separation of $\alpha a_{\mathrm{BC}}$ in two different groups and suggests an upper limit value of $\mathrm{K} / \mathrm{BC}_{\mathrm{Th}}=0.78$, under which $\mathrm{BC}_{\mathrm{Th}}$ presented reasonable values. The authors also suggest a similar effect associated with $\mathrm{Na}$, but we did not find any association between the ratio $\mathrm{Na} / \mathrm{BC}_{\mathrm{Th}}$ and $\alpha a_{\mathrm{BC}}$. Thus samples with $\mathrm{K} / \mathrm{BC}_{\mathrm{Th}}<0.78$ were selected for the measurement of $\alpha a_{\mathrm{BC}}$ in this data set. This procedure needs to be studied and generalized for other data sets, suggesting a quality assurance protocol for thermal BC data.

The $\mathrm{K} / \mathrm{BC}_{\mathrm{Th}}=0.78$ upper limit is also in accordance with the optical modeling calculations presented in section 2. As showed in Figure 3, the maximum value for a monodispersed particle size distribution using the layered-sphere model is about $30 \mathrm{~m}^{2} \mathrm{~g}^{-1}$. Integrating over a realistic accumulationmode size distribution for biomass burning particles [e.g., Reid et al., this issue (b)], this value reaches a maximum of about 25 $\mathrm{m}^{2} \mathrm{~g}^{-1}$. Similar values were found for a packed cluster of BC particles embedded in a nonabsorbing matrix. Also, $\alpha a_{\mathrm{BC}}$ values commonly reported in the literature are generally below 25 $\mathrm{m}^{2} \mathrm{~g}^{-1}$ [e.g., Liousse et al., 1993; Horvath, 1993a; Roessler and Faxvog, 1980]. However, Chylek et al. [1995] discuss the possibility of $\mathrm{BC}$ mass absorption efficiency reaching values up to $100 \mathrm{~m}^{2} \mathrm{~g}^{-1}$ in special circumstances (e.g., water droplets with a small $\mathrm{BC}$ core out of center).

Using the layered-sphere model described in section 2, the optical properties of the aerosol particles were estimated on the basis of the parameters measured on the UW C131-A aircraft, namely, simultaneous measurements of light absorption and mass concentrations (Nuclepore and Teflon filters), $\mathrm{BC}_{\mathrm{Th}}$ (quartz filters), particle size distribution with a passive cavity aerosol spectrometer probe (PCASP) and a differential mobility particle sizer (DMPS), and total light scattering and backscattering at three wavelengths. The PCASP measures particles with diameter between 0.1 and $3.0 \mu \mathrm{m}$, while the DMPS measures particles diameter in the range of $0.01-0.6$ $\mu \mathrm{m}$. Five cases were modeled assuming a constant fraction of $\mathrm{BC}$ for all the particles in the size distribution. For the $\mathrm{BC}$ core, a complex refractive index of $2.0-1.0 l$ at $0.55 \mu \mathrm{m}$ was assumed, with a density of $1.85 \mathrm{~g} \mathrm{~cm}^{-3}$. Particle size distributions were considered to be lognormal. Figure 9 shows a comparison between the measured values of $\alpha a_{\mathrm{BC}}$ versus the relative amount of thermal $\mathrm{BC}$ in each sample separating cases with $\mathrm{K} / \mathrm{BC}_{\mathrm{Th}}<0.78$. Calculated results using the layeredsphere model with three measured particle size distributions are superimposed on the experimental values, as well as the asymptotic $\alpha a_{\mathrm{BC}}$ value for pure BC particles with similar particle size distributions. In this case, the $\alpha a_{\mathrm{BC}}$ values for pure $\mathrm{BC}$ particles represent external mixing between $\mathrm{BC}$ and non- 

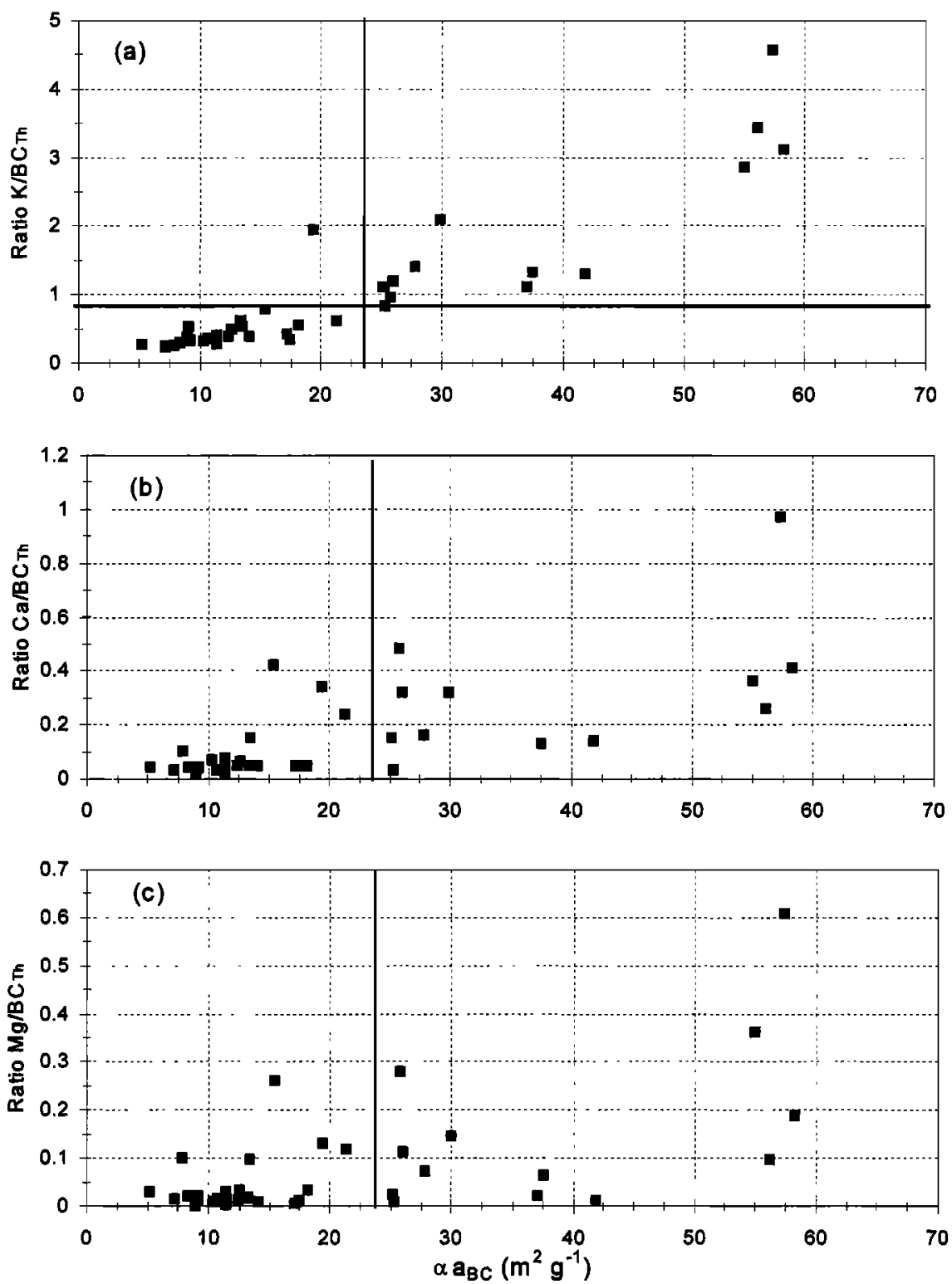

Figure 8. Ratios (a) $\mathrm{K} / \mathrm{BC}_{\mathrm{Tl}}$, (b) $\mathrm{Ca} / \mathrm{BC}_{\mathrm{Th}}$, and (c) $\mathrm{Mg} / \mathrm{BC}_{\mathrm{Th}}$ versus $\alpha a_{\mathrm{BC}}$ for all the analyzed samples. The upper limit $\mathrm{K} / \mathrm{BC}_{\mathrm{Th}}=0.78$ is pointed in the figure showing the separation for reliable $\alpha a_{\mathrm{BC}}$ values.

absorbing particles. The modeled results can account for $\alpha a_{\mathrm{BC}}$ values between 5 and $25 \mathrm{~m}^{2} \mathrm{~g}^{-1}$, which explains about $70 \%$ of the data set and all $\alpha a_{\mathrm{BC}}$ values for $\mathrm{K} / \mathrm{BC}_{\mathrm{Th}}<0.78$. Table 1 shows general characteristics of the studied samples. There is no clear correlation between $\alpha a_{\mathrm{BC}}$ and location, type of combustion, or type of sample. On the other hand, SEM pictures of the samples also suggest a separation in two groups of particles with distinct micromorphology. The first group, which has low $\alpha a_{\mathrm{BC}}$ values, has spherical-like shape and relatively homogeneous particles (Figure 10a). The second group, which has high $\alpha a_{\mathrm{BC}}$ values, shows a large concentration of nonspherical particles and compact clusters of small particles (Figure 10b), similar to the one shown in Figure 5.

Figure 11 shows an example of the particle size distribution, and the DMPS "hot" size distribution, which corresponds to the size distribution of the same sample after heating the aerosol to $340^{\circ} \mathrm{C}$ (which causes most volatile compounds to evaporate; for example, organics, ammonium sulfate, etc.). The comparison between the "hot" and the "cold" size distributions suggested a predominance of internal mixing between volatile and nonvolatile particles. Despite the large difference in the size distributions for the "hot" and "cold" samples, the total number of particles was reduced by only $15 \%$ by heating, showing that most of the particles were not completely volatile and suggesting internal mixing. Figure 11 shows good agreement between particle count distribution measured with the DMPS and PCASP, despite the fact that the DMPS measures particle sizes on the basis of the electrical mobility of the particles, and the PCASP measurements are derived from light scattering. Volume size distributions calculated from the measured number size distributions, in combination with mass concentration measurements, were used to estimate particle density. Backscattering measurements from the nephelometer were used to estimate the asymmetry factor $(g)$ as a function 
Table 1. Characteristics of SCAR-B Samples Listed in Order of BC Mass Absorption Efficiency

\begin{tabular}{|c|c|c|c|c|c|}
\hline Sample & $\begin{array}{l}\text { Location of } \\
\text { Sampling }\end{array}$ & Type of Sample & MCE & $\begin{array}{l}\text { BC Mass } \\
\text { Absorption } \\
\text { Efficiency, } \\
\mathrm{m}^{2} \mathrm{~g}^{-1}\end{array}$ & $\underset{\%}{\mathrm{BC}_{\mathrm{Th}} / \mathrm{TPM},}$ \\
\hline 1 & Brasília & emission factor & & 5.2 & 5.85 \\
\hline 2 & Cuiabá & regional haze & & 7.2 & 12.94 \\
\hline 3 & Cuiabá & $\mathrm{Cu}$ processed (fire top) & & 7.9 & 4.32 \\
\hline 4 & Marabá & smoldering (EF) & 0.881 & 8.3 & 7.10 \\
\hline 5 & Porto Velho & background & & 8.9 & 5.56 \\
\hline 6 & Brasília & emission factor & 0.949 & 9.1 & 5.18 \\
\hline 7 & Marabá & in cloud & & 9.2 & 14.07 \\
\hline 8 & Cuiabá & regıonal haze & & 10.3 & 5.98 \\
\hline 9 & Porto Velho & background & & 10.7 & 2.25 \\
\hline 10 & Porto Velho & regional haze & & 11.4 & 4.60 \\
\hline 11 & Cuiabá & regional haze & & 11.4 & 4.59 \\
\hline 12 & Marabá & regional haze & & 11.4 & 5.76 \\
\hline 13 & Brasília & emission factor & & 12.3 & 9.73 \\
\hline 14 & Brasília & emission factor & 0.936 & 12.5 & 5.78 \\
\hline 15 & Brasílıa & emission factor & 0.958 & 13.3 & 10.74 \\
\hline 16 & Marabá & emission factor & 0.896 & 13.4 & 7.00 \\
\hline 17 & Porto Velho & regional haze & & 14.1 & 5.03 \\
\hline 18 & Porto Velho & emission factor & 0.894 & 15.4 & 4.19 \\
\hline 19 & Cuiabá & regional haze & & 17.1 & 1.85 \\
\hline 20 & Marabá & emission factor & 0.883 & 17.4 & 4.41 \\
\hline 21 & Marabá & emission factor & 0.828 & 18.1 & 5.05 \\
\hline 22 & Marabá & emission factor & 0.946 & 19.3 & 5.82 \\
\hline 23 & Marabá & emission factor & & 21.3 & 6.51 \\
\hline 24 & Marabá & in cloud & & 25.1 & 7.98 \\
\hline 25 & Porto Velho & emission factor & 0.975 & 25.2 & 11.82 \\
\hline 26 & Cuiabá & smoke column & & 25.7 & 3.77 \\
\hline 27 & Marabá & emission factor & 0.920 & 25.9 & 5.41 \\
\hline 28 & Porto Velho & regional haze & & 27.8 & 1.87 \\
\hline 29 & Brasília & emission factor & 0.949 & 29.9 & 4.00 \\
\hline 30 & Marabá & emission factor & & 37.0 & 2.20 \\
\hline 31 & Marabá & regional haze & & 37.5 & 2.33 \\
\hline 32 & Cuiabá & regional haze & & 41.9 & 0.57 \\
\hline 33 & Marabá & emission factor & 0.966 & 55.0 & 1.89 \\
\hline 34 & Marabá & in cloud & & 56.2 & 3.15 \\
\hline 35 & Marabá & emission factor & & 57.3 & 1.93 \\
\hline 36 & Marabá & emission factor & 0.855 & 58.3 & 2.23 \\
\hline
\end{tabular}

Sample numbers are the same as in Table 2. Note that MCE corresponds to modified combustion efficiency.

of the particle geometric standard deviation, using the expression proposed by Marshall et al. [1995]. The real refractive indices of the nonabsorbing shells were estimated in an iterative process to fit the scattering coefficient $\left(\sigma_{v}\right)$ measured by the nephelometer at a wavelength of $0.55 \mu \mathrm{m}$. The amount of $\mathrm{BC}$ was allowed to vary until it fitted the absorption coefficient $\left(\sigma_{a}\right)$ estimated from the Nuclepore filters. After convergence, $\sigma_{s}, \sigma_{a}$, the BC content, $g$, and $\alpha a_{\mathrm{BC}}$ were compared with the measured values.

Table 2 shows comparisons between some of the modeling results and the measurements. The average real refractive index obtained from the model was $1.48 \pm 0.08$ (varying between 1.37 and 1.59). A real refractive index as small as 1.37 can be explained by possible underestimates of $\sigma_{s}$ by the nephelometer, uncertainties in the particle size distribution, or inconsistencies between the modeled particle structure and shape (layered sphere) and the actual particles. However, the singlescattering albedo $\left(\omega_{0}\right)$ and the asymmetry factor are relatively well produced by the model. The $\mathrm{BC}$ content estimated from the model showed poor agreement with the measured $\mathrm{BC}_{\mathrm{Th}}$. Large uncertainties in the $\mathrm{BC}$ determination from the model are associated to some extent with large values of $\alpha a_{\mathrm{BC}}$ de-

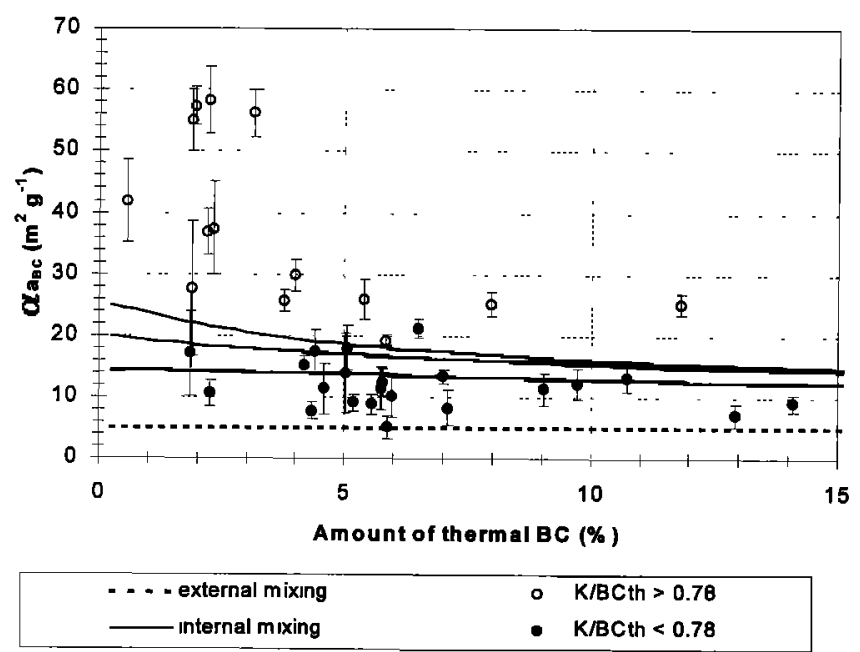

Figure 9. Measured and modeled BC mass absorption efficiencies ( $\alpha a_{\mathrm{BC}}$ ) at $\lambda=0.55 \mu \mathrm{m}$ versus the amount of $\mathrm{BC}$ in the sample. Solid curves represent the modeled $\alpha a_{\mathrm{BC}}$ for three particle size distributions given in Table 1 . The dashed line is the asymptotic limit for $\alpha a_{\mathrm{BC}}$ assuming external mixing and for the measured particle size distributions. 

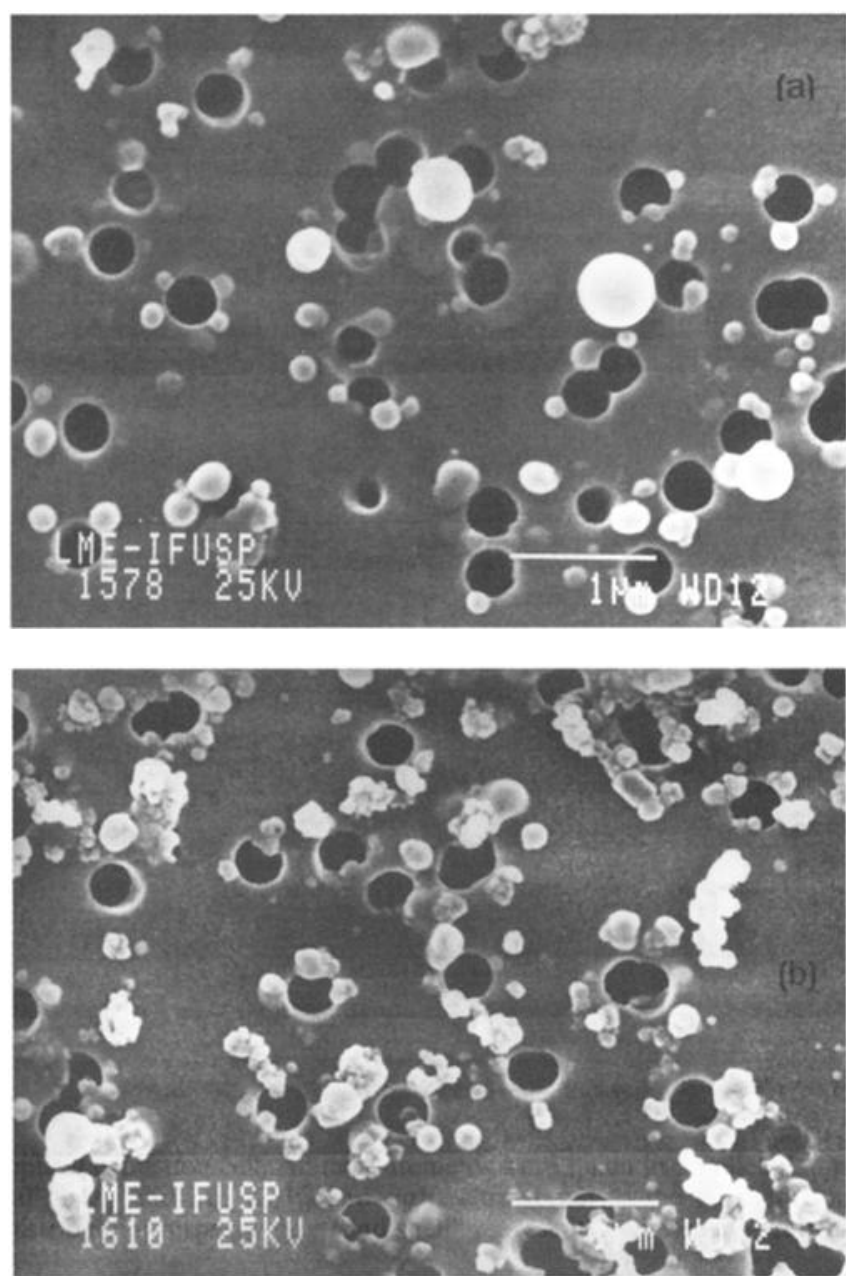

Figure 10. (a) Typical scannıng clectron microscopy (SEM) photograph of acrosol particles with low $\alpha a_{136}$ values. Most of the particles have spherical-like shape. (b) Typical SEM photograph of smoke particles with high $\alpha a_{\mathrm{BC}}$ values. The photograph shows a large concentration of nonspherical particles and compact clusters of small particles similar to the one shown in Figure 5.

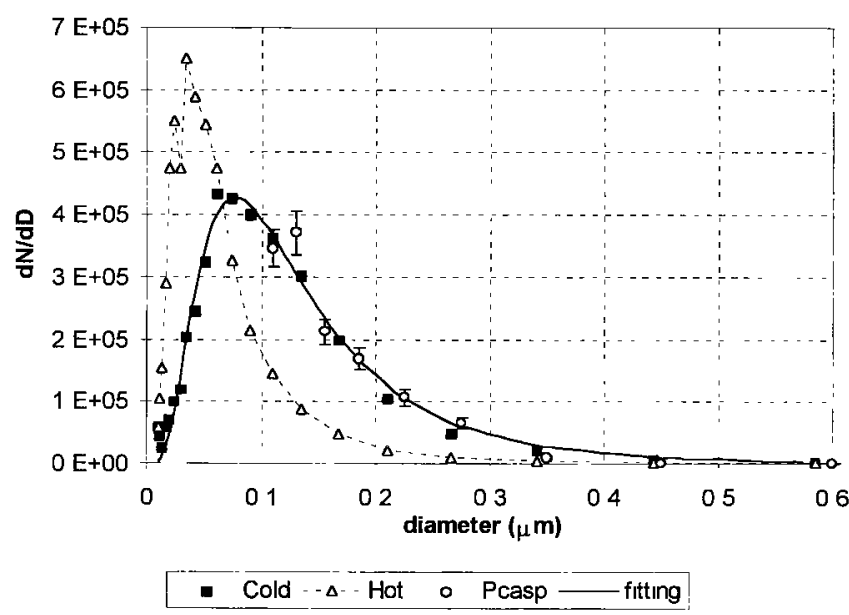

Figure 11. Measured particle size distributions from the DMPS (differential mobility particle sizer) and from the PCASP (passive cavity aerosol spectrometer probe). DMPS cold corresponds to measurements at ambient temperature and hot to measurements at $340^{\circ} \mathrm{C}$. The solid curve represents a lognormal fit to the combined DMPS "cold" plus PCASP data. The difference between DMPS results cold and hot suggests predominance of internal mixing.

rived from the combination of the thermal technique and optical absorption measurements (e.g., sample 27). Recall that the model cannot explain values of $\alpha a_{\mathrm{BC}}$ larger than $25 \mathrm{~m}^{2} \mathrm{~g}^{-1}$ for the particle size distributions considered. Even for monodisperse particles an optimized particle size would provide a maximum value of $\alpha a_{\mathrm{Bc}}$ around $30 \mathrm{~m}^{2} \mathrm{~g}$ ', as shown in Figure 3.

\section{Conclusions}

Black carbon mass absorption efficiency $\left(\alpha a_{\mathrm{BC}}\right)$ depends strongly on particle mixing, size distribution, and morphology of the particles. In agreement with the literature, results show

Table 2. Optical and Physical Properties of Aerosol Particles Measured and Calculated Using Mie Theory in Actual Samples Collected During SCAR-B Aboard the UW C131-A Aircraft

\begin{tabular}{|c|c|c|c|c|c|c|c|c|c|c|}
\hline \multirow[b]{2}{*}{ Results } & \multicolumn{2}{|c|}{ Sample 4} & \multicolumn{2}{|c|}{ Sample 27} & \multicolumn{2}{|c|}{ Sample 10} & \multicolumn{2}{|c|}{ Sample 7} & \multicolumn{2}{|c|}{ Sample 20} \\
\hline & Measured & Calculated & Measured & Calculated & Measured & Calculated & Measured & Calculated & Measured & Calculated \\
\hline Type & smolderıng, & Marabá & flamıng, $M$ & Irabá & haze, Porto & Velho & in cloud, $\mathrm{N}$ & larabá & smoldering & , Marabá \\
\hline$D g$ & 0.12 & & 0.087 & & 0.19 & & 0.12 & & 0.11 & \\
\hline$\sigma g$ & 1.89 & & 1.87 & & 1.78 & & 1.79 & & 1.89 & \\
\hline$D g V$ & 0.27 & & 0.25 & & 0.52 & & 0.25 & & 0.27 & \\
\hline$\sigma g V$ & 1.63 & & 1.62 & & 1.78 & & 1.62 & & 1.67 & \\
\hline$\rho, \mathrm{g} \mathrm{cm}^{-3}$ & 1.21 & & 1.00 & & 1.20 & & 1.28 & & 1.04 & \\
\hline Rind shell & & 1.440 & & 1.525 & & 1.370 & & 1.587 & & 1.460 \\
\hline$\sigma \mathrm{s}, \mathrm{m}^{-1}$ & $6.4 \mathrm{E}-4$ & $6.4 \mathrm{E}-4$ & $1.11 \mathrm{E}-3$ & $1.11 \mathrm{E}-3$ & $4.72 \mathrm{E}-4$ & $4.72 \mathrm{E}-4$ & $4.9 \mathrm{E}-4$ & $4.9 \mathrm{E}-4$ & $8.70 \mathrm{E}-4$ & $8.66 \mathrm{E}-4$ \\
\hline$\sigma a, \mathrm{~m}^{1}$ & $1.30 \mathrm{E}-4$ & $1.30 E-4$ & $3.79 E-4$ & $3.80 E-4$ & $6.75 \mathrm{E}-5$ & $7.05 E-5$ & $1.54 \mathrm{E}-4$ & $1.54 E-4$ & $1.84 E-4$ & $1.84 \mathrm{E}-4$ \\
\hline$\omega_{0}$ & 0.83 & 0.83 & 0.74 & 0.74 & 0.87 & 0.87 & 0.76 & 0.76 & 0.83 & 0.83 \\
\hline$\% \mathrm{BC}_{T h}$ & 7.1 & 4.1 & 5.41 & 9.6 & 4.60 & 4.3 & 14.07 & 7.8 & 4.41 & 5.3 \\
\hline$g$ & 0.533 & 0.550 & 0.485 & 0.490 & 0.617 & 0.689 & 0.52 & 0.50 & 0.534 & 0.55 \\
\hline$\alpha a_{\mathrm{BC}}, \mathrm{m}^{2} \mathrm{~g}^{-1}$ & 8.3 & 15.3 & 25.9 & 15.2 & 11.4 & 12.5 & 9.2 & 16.6 & 17.4 & 15.3 \\
\hline
\end{tabular}

The Mie calculations were performed for layered-sphere particles using the code developed by Ackerman and Toon, further improved and made available by W. WIscombe, NASA GSFC. Size distributions were measured by the PCASP and DMPS instruments, $\sigma s$ and $g$ was obtained by a onboard nephelometer $(\lambda=0.55 \mu \mathrm{m})$, and $\sigma a$ was obtained by a reflectance technique applied to Nuclepore filters intercalibrated with an optical extinction cell. All measurements were taken in parallel. Sample numbers are the same as presented in Table 1 . Read $6.4 \mathrm{E}-4$ as $6.4 \times$ $10^{-4} . D g$ and $\sigma g, D g V$, and $\sigma g V$, correspond to the geometric mean diameter and standard deviation of the number and volume size distrıbution, respectively, "Rınd shell" represents estımates for refractıve index of the nonabsorbing shell. 
that the mass of $\mathrm{BC}$ was underestimated for samples with high-K content producing unrealistic high values for $\mathrm{BC}$ mass absorption efficiencies. An empirical upper limit $\mathrm{K} / \mathrm{BC}_{\mathrm{Th}}=$ 0.78 has been defined in this paper to select reliable results for mass absorption efficiencies. Below this value the measured mass of $\mathrm{BC}_{\mathrm{Th}}$ provided good results for $\alpha a_{\mathrm{BC}}$. Similar behaviors were found for concentrations of $\mathrm{Ca}$ and $\mathrm{Mg}$.

The $\mathrm{BC}$ mass absorption efficiency $\left(\alpha a_{\mathrm{BC}}\right)$ for particles from biomass burning in Brazil ranged from 5.2 to $19.3 \mathrm{~m}^{2} \mathrm{~g}^{-1}$ with an average value of $12.1 \pm 4.0 \mathrm{~m}^{2} \mathrm{~g}^{-1}$. In addition to the layered sphere model for internal mixtures, a packed cluster model was proposed for biomass burning particles from regional haze. For a particular case with BC/TPM $=0.64$, the packed cluster structure presented $\alpha a_{\mathrm{BC}}$ values up to $35 \%$ higher than results obtained for the layered sphere model for particles with radius above $0.1 \mu \mathrm{m}$. Modeled results using cluster and layered sphere models plus Mie theory accounted for $\alpha a_{\mathrm{BC}}$ values between 5 and $25 \mathrm{~m}^{2} \mathrm{~g}^{-1}$ depending on the size distribution and $\mathrm{BC}$ fraction. The modeled results provided good estimates for the optical properties of the biomass burning aerosol collected in Brazil. The large range of $\alpha a_{\mathrm{BC}}$ measured for biomass burning particles must be taken into account when using optical measurements to determine the mass of BC. An accurate determination of the mass of $\mathrm{BC}$ through optical methods depends on knowing the value of $\alpha a_{\mathrm{BC}}$ very well for each particular type of particles. Estimates of $\alpha a_{\mathrm{BC}}$ are also important to connect $\mathrm{BC}$ emissions with light absorption by particles in the atmosphere.

There was no clear correlation between $\alpha a_{\mathrm{BC}}$ and location, type of combustion, or type of sample. Samples with low $\alpha a_{\mathrm{BC}}$ values contained mostly homogeneous particles with sphericallike shape. Samples containing asymmetrical particles and cluster-like structures showed higher $\alpha a_{\mathrm{BC}}$ values. This characteristic was attributed either to the particular internal mixing contributing to enhance the light absorption properties or to earlier volatilization of $\mathrm{BC}$ particles during the thermal measurements also enhanced by the particular internal mixing.

Acknowledgments. J. V. Martins thanks the Brazlian agencies FAPESP (project 93/5017-3 and 96/2672-9) and CAPES (project 437/ 95) for financial support. The University of Washington's participation in SCAR-B was supported by the following grants: NASA NAGW3750 and NAG 11709; NSF ATM-9400760, ATM-9412082, and ATM9408941; NOAA NA37RJ0198AM09; and EPA CR822077. We thank Alcides C. Ribeiro, Ana L. Loureiro, and Tarsis Germano for assistance durng sampling and analysis. We are very grateful to Hélène Cachier for her careful review and important discussions improving the contents of the paper.

\section{References}

Ackerman, P. T., and O. B. Toon, Absorption of visible radiation in the atmosphere containing mixtures of absorbing and nonabsorbing particles, Appl. Opt., 20, 3661-3667, 1981.

Bohren, C. F., and D. R. Huffman, Absorption and Scattering of Light by Small Particles, pp. 213-219, Wiley Intersci., New York, 1983.

Cachier, H., M. P. Brémond, and P. Buat-Ménard, Determination of atmospheric soot carbon with a simple thermal method, Tellus, Ser. $B, 41,379-390,1989$.

Campbell, D., and T. Cahill, Response to "Comment on "Measurement of aerosol absorption coefficient from Teflon filters using the integrating plate and integrating sphere techniques' by D. Campbell, S. Copeland, and T. Cahill" by A. Clarke, J. Ogren, and R. Charlson, Aerosol Sci. Technol., 24, 225-229, 1996.

Campbell, D., S. Copeland, and T. Cahill, Measurements of aerosol coefficient from Teflon filters using integrating plate and integrating sphere techniques, Aerosol Sci. Technol., 22, 287-292, 1995.
Chylek, P., G. Videen, D. Ngo, R. G. Pinnick, and J. D. Klett, Effect of black carbon on the optical properties and clımate forcing of sulfate aerosols, J. Geophys. Res., 100, 16,325-16,332, 1995.

Clarke, A. D., Integrating sandwich: A new method of measurement of the light absorption coefficient of atmospheric particles, Appl. Opt., $21,3011-3021,1982 \mathrm{a}$.

Clarke, A. D., Effects of filter internal reflection coefficient on light absorption measurements made using the integrating plate method, Appl. Opt., 21, 3021-3031, $1982 \mathrm{~b}$.

Clarke, A. D., K. J. Noone, J. Heintzenberg, S. G. Warren, and D. S. Covert, Aerosol light absorption measurement techniques: Analysis and intercomparisons, Atmos. Environ., 21, 1455-1465, 1987.

Clarke, A. D., J. Ogren, and R. Charlson, Comment on "Measurement of aerosol absorption coefficient from Teflon filters using the integrating plate and integrating sphere techniques" by D. Campbell, S. Copeland, and T. Cahill, Aerosol Sci. Technol., 24, 221-224, 1996.

Delumyea, R. G., L. C. Chu, and E. Macıas, Determination of elemental carbon component of soot in ambient aerosol samples, Atmos. Environ., 14, 647-652, 1980.

Draine, B. T., and P. J. Flatau, Discrete dipole approximation for scatterıng calculations, J. Opt. Soc Am. A., 11, 1491-1499, 1994.

Hallet, J., J. G. Hudson, and C. F. Rogers, Characterization of combustion aerosols for haze and cloud formation, Aerosol Sci. Technol., 10, 70-83, 1989.

Hanel, G., Single scattering albedo, asymmetry parameter, apparent refractive index, and apparent soot content of dry atmospheric particles, Appl. Opt., 27, 2287-2294, 1988.

Hanel, G., and C. Hillenbrand, Calorimetric measurements of optical absorption, Appl. Opt., 28, 510-516, 1989.

Hanel, G., R. Busen, C. Hillenbrand, and R. Schloss, Light absorption measurements: New techniques, Appl. Opt., 21, 382-386, 1982.

Hansen, A. D. A., H. Rosen, and T. Novakov, Real time measurement of the aerosol particles, Appl. Opt., 21, 3060-3062, 1982.

Hobbs, P. V., Summary of types of data collected on the University of Washington's Convair C-131A aircraft in the Smoke, Clouds and Radiation-Brazıl (SCAR-B) field study from 17 August-20 September 1995, Cloud and Aerosol Res. Group, Dep of Atmos. Sci., Univ. of Washington, Seattle, March 1996. (Also available on http:// cargsun2.atmos.washington.edu/.)

Horvath, H., Atmospheric light absorption-A review, Atmos. Envlron., Ser. $A, 27(3), 293-317,1993$ a.

Horvath, H., Comparison of measurements of aerosol optical absorptıon by filter collection and a transmissometric method, Atmos. Environ., Ser. A, 27, 319-325, 1993b.

Japar, S. M., W. W. Brachaczek, R. A. Gorse, J. M. Norbeck, and W. R. Pierson, The contribution of elemental carbon into the optıcal properties of rural atmospheric aerosols, Atmos. Environ., 20, 1281$1289,1986$.

Lindberg, J. D., and L. S. Laude, Measurement of the absorption coefficient of atmospheric dust, Appl. Opt., 13, 1923-1927, 1977.

Liousse, C., H. Cachier, and S. G. Jennings, Optical and thermal measurements of black carbon aerosols content in different environments: Variations of the specific attenuation cross section, sigma (o), Atmos. Environ., Ser. A, 27, 1203-1211, 1993.

Marshall, S. F., D. S. Covert, and R. J. Charlson, Relationship between asymmetry parameter and hemispheric backscatter ratio: Implicatıons for climate forcing by aerosols, Appl. Opt.. 34, 6306-6311, 1995.

Martins, J. V., P. V. Hobbs, R. E. Weiss, and P. Artaxo, Sphericity and morphology of smoke particles from biomass burning in Brazil, $J$. Geophys. Res., this issue.

Novakov, T., and C. E. Corrigan, Thermal characterization of biomass smoke partıcles, Mikrochim. Acta, 119, 157-166, 1995.

Patterson, E. M., and B. T. Marshall, Diffuse reflectance and transmission measurements of aerosol absorption, in Light Absorption by Aerosol Partcles, edited by H. E. Gerger and E. E. Hindman, Spectrum, Hampton, Va., 1982.

Petzold, A., and R. Niessner, Method comparison study on sootselective techniques, Mikrochim. Acta, 117, 215-237, 1995.

Purcell, E. M., and C. R. Pennypacker, Scattering and absorption of light by nonspherical dielectric grains, Astrophys. J., 186, 705-714, 1973.

Reid, J. S., and P. V. Hobbs, Physıcal and optical properties of young smoke from individual biomass fires in Brazil, J. Geophys. Res., this issue.

Reid, J. S., P. V. Hobbs, C. Liousse, J. V. Martins, R. E. Weiss, and 
T. F. Eck, Comparisons of techniques for measuring shortwave absorption and the black carbon content of aerosols from biomass burning in Brazil, J. Geophys. Res., this issue (a).

Reid, J. S., P. V. Hobbs, R. J. Ferek, D. R. Blake, J. V. Martins, M. R. Dunlap, and C. Liousse, Physical, chemical, and optical properties of regional hazes dominated by smoke in Brazil, J. Geophys. Res., this issue (b).

Roessler, D. M., and F. R. Faxvog, Optical properties of agglomerated acetylene smoke particles at $0.5145 \mu \mathrm{m}$ and $10.6 \mu \mathrm{m}$ wavelengths, $J$. Opt. Soc. Am., 70, 230-235, 1980.

Ruoss, K., R. Dlugi, C. Weigl, and G. Hanel, Intercomparison of different Aethalometers with an absorption technique: Laboratory calibrations and field measurements, Atmos. Environ., 27A(8), 12211228, 1993.

Weiss, R. E., and P. V. Hobbs, Optical extinction properties of smoke from the Kuwait oil fires, J. Geophys. Res., 97, 14,537-14,540, 1992.
P. Artaxo and J. V. Martins, Instituto de Física, Universidade de São Paulo, C.P. 66318, CEP 05315-970, São Paulo, Brazil. (e-maıl: vanderlei@if.usp.br)

P. V. Hobbs and J. S. Reid, Department of Atmospheric Sciences, University of Washington, Seattle, WA 98195-1640.

Y. Kaufman, NASA Goddard Space Flight Center, Code 913, Greenbelt, Maryland 20771.

C. Liousse, Centre de Faibles Radioactivites, CNRS-CEA, Av de la Terrasse, 91198 Gif sur Yvette, France.

(Receıved October 6, 1997; revised July 1, 1998; accepted August 3, 1998.) 